African Research Review vol.1(1)

\title{
Listening Effectively For Results in an ESL/EFL Classroom.
}

\author{
Nneka Umera-Okeke
}

\begin{abstract}
:
Unlike writing and speaking, the listening skill is often overlooked probably because they are hard to observe and measure. Children and students are expected to listen but are never taught to listen as they are taught to speak, read and write. This negligence has contributed a lot to students' poor performance in schools and a breakdown in everyday communication. This study tries to differentiate between hearing and listening; looks into the different listening styles exhibited by people; gives reasons why people are poor listeners and how to develop effective listening habit. It also states what an ideal listening process ought to be; what people listen to and how to improve listening through active and critical listening.
\end{abstract}

\section{Introduction}

Listening is a rudiment to communication as no communication is possible without effective listening. It is a skill that starts early in ones life. Very young babies, as early as two months old show evidence of listening. You observe them react to sounds, their mothers' voices and even cry when scolded. Various authors have tried to define listening and state what it entails. Wolvin (1995) quoted the International Listening Association's definition of listening as "the process of receiving constructing meaning from and responding to spoken and/or nonverbal messages". We may be surprise to hear that responding to nonverbal messages is also part of listening. Nonverbal cues such as body movement, frowning and smiling will help you to interpret speaker's messages. When you watch and listen to someone speak, you often understand more than when you only listen. This is why television broadcast is audio-visual while radio broadcast is just audio and people prefer the former to the latter. Listening is a mental process that requires concentrating on sound, deriving meaning from it, and reacting to it. Yagang (1996) defined listening as:

the ability to identify and understand what others are saying. This involves understanding a speaker's accent or pronunciation, his grammar and his vocabulary, and grasping his meaning.

This definition also entails extracting meaning from verbal and nonverbal cues.

Hybels and Weaver II (2001) in trying to state the complex nature of listening compared it to hearing and stated:

Hearing is a physiological process involving the various parts of the ear, whereas listening is a more complicated perceptual process involving your total response to others, including verbal as well as nonverbal communication.

Fruehling and Lacomber (2006) did not state differently when they said that: Hearing is a physical process; when sound waves reach your ears and send messages to your brain, you are hearing. Listening is an intellectual process that combines hearing with evaluating; listening often leads to a follow-up. 
This definition implies that hearing is a passive process. Listening, though a complex activity should be taken seriously. Business people who fail to listen attentively to their customers' wants lose them; we spend our time listening to telephone conversations, informal speeches, lectures, different kinds of performances, seminars chats and a lot others. One needs sophisticated listening skills to receive information and to understand it. Being a psychological process, it involves the mind as well as the sense organs; "listening involves sensing, selecting, interpreting, retaining and retrieving aurally acquired information" (Pandey 2005).

\section{Listening Styles}

There are different ways of learning and different ways of listening.

Researches by Youaver and Kirtly (1995) revealed four different kinds of learning styles. They include:

1. People listening style

2. Action listening style

3. Content listening style and

4. Time-style listening

\section{People Listening Style}

In People Listening Style, the listener shows concern for other people's feelings. He looks out for common interest and respond to emotions. Couples, families, intimate friends indulge in this type of listening.

\section{Action listening Style}

The listener is interested in precision, error-free presentation and grows impatient with any form of disorganization. A boss indulges in this kind of listening towards his subordinates especially as regards reports about the functioning of the different parts/ sections of the organization. Some instructors are action listener and have no time for lazy students.

\section{Content Listening Style}

This kind of listening requires emotional detachment on the part of the listener. He evaluates the information before passing judgment or taking decisions. For instance, a doctor who is a content listener listens to his other colleagues on how a particular patient should be treated. At the end he weighs what he heard through his expertise knowledge and decides to go on with it or seek alternative way.

\section{Time Style Listener}

This is listening that is dependent on time. The listener wants brief and hurried interaction with others and does not pretend about letting the communicator know that. News people who are always working around the clock are time-style listeners because they need to get information quickly and efficiently for their television newscast or to go to the press for their newspaper.

Campbell (1997) has another point of view regarding listening styles. He identified three basic listening modes: Combative, Attentive and Reflective Modes.

A Combative listener does not want to hear other people's point of view. He always wants to promote himself in every discussion.

Attentive Listeners are interested in other people's view. They listen and they care. They indulge in people-listening style.

A Reflective Listener takes an active role in the communication process. He is not passive but rather he thinks critically about the topic or message he receives. It 
brings about real learning. This listening style can be seen as Youaver and Kirtley's Content listening style.

Of what benefit are these listening styles to communication? A skillful listener is one who adapts his listening style to the environment and circumstances. A student should study his instructors to know what they are like as regards listening. One should adapt a people-listening style when listening to a co-worker who is troubled or aggrieved. Learn the listening style of people you work with as it determines your communication with them. When you want a critical reaction to a paper you have written, you go to a content or reflective style listener and when you are disturbed or want to lay a complaint about work conditions, you go to an attentive/people style listener.

Youaver and Kirtley (1995) went further to state that at times, a person's listening style is dependent on the culture he or she comes from:

Americans were the most people-centred and were likely to pay careful attention to the feelings of the people they were talking to while Israelis concentrated more on the accuracy of the messages. Germans were the most active listeners and often inter-spersed questions as the listened.

One needs a variety of listening skills for listening requires as much skill as speaking and writing. The best listener is someone who is not easily bored and who has some basic skills in acquiring and organizing information.

\section{Reasons for Poor Listening}

A lot of problems may cause us not to listen attentively. Some listening errors are unintentional while some are deliberately created. It could physical barriers (poor audio system, hearing loss etc.) or mental barriers which include selective listening, inattention, apathy or hostility. Whichever way, listeners should be familiar with some ways through which listening could go astray. Hybels and Weaver II (2001) identified the following as the reasons why people have problems with listening:

\section{(a) Cognitive Dissonance}

This is a psychological theory that applies to communication. It occurs "when a person feels conflict if he or she holds two or more attitudes that are in opposition to each other". New information you are listening to may be in conflict with your already held beliefs and it may make for poor listening. People with dissonance problem are inflexible listeners who refuse to listen to a speaker who has said or implied something they disagree with especially something that contradicts their value and belief system. To reduce dissonance, you should ignore the information that is causing the conflict and listen on.

\section{(b) Anxiety:}

High anxiety level causes psychological noise to an individual and though he pretends to be listening, he is only hearing without understanding. Anxiety exists in classroom setting. A teacher who threatens the students with an on-coming test at the end of the lesson may have succeeded in raising their anxiety thereby making them not to listen attentively in the rest of the lesson.

\section{(c) The Controlling Listener:}

These are people who prefer to talk always than to listen. They interrupt discussions very often to talk about themselves and their experiences. They may also be 
called combative listeners. The conversation they indulge in may be seen as a monologue. A controlling listener ignores all nonverbal cues they get from others showing lack of interest in what they are saying. They are always boastful. A good listener should observe conversation turns.

\section{(d) The Passive Listener:}

This is listening without interest. "Well let me just sit down and listen. This subject is difficult, I know I can never pass it"; "Here he comes again, dirty pig". These are the thinking of some students in the classroom. They show lack of interest from the beginning either because they hate the subject or the teacher. Their minds wander in a completely new direction. This set of people is called "closed minded listeners" by Fruehling and Lacombe (2006). They are not interested in learning from the speaker.

Other kinds of internal distractions that may cause poor listening are insincerity, boredom and inattention. Insincere listeners are those that listen to the words not the message. They usually avoid eye contact with the speaker and could not have seen the body movements that accompany the message.

Bored listeners have no interest in the subject. They are often impatient with and hostile to the speaker.

Inattentive listeners occupy themselves with something else while the speaker is speaking. Little things that happen around them like the ringing of the telephone, passing conversation constitute distractions to them.

One should try and develop effective listening habits which takes a good deal of selfdiscipline. Good listeners should fight distractions by showing attention, questioning, commenting, taking notes and ignoring all other outside stimuli. Always arrive early for presentations/lectures and have your sit in front or at other vantage positon where you can hear the speaker well and observe the nonverbal cues that accompany his message.

\section{The Processes of Listening}

Having looked at obstacles to effective listening, it becomes pertinent to look at the processes of an ideal listening situation. Willis (1981:134) lists a series of micro-skills of listening, which she calls "enabling skills". They are:

- Predicting what people are going to talk about.

- Guessing at unknown words or phrases without panicking.

- Using one's own knowledge of the subject to help one understand.

- Identifying relevant points; rejecting irrelevant information.

- Retaining relevant points (note-taking, summarizing).

- Recognizing discourse markers, e.g., well, oh, another thing is..., now, finally etc.

- Recognizing cohesive devices, e.g. such as 'and', 'which', other linking words, pronouns, references etc.

- Understanding different intonation patterns and uses of stress, which give clue to meaning and social setting.

- Understanding inferred information, e.g., speaker's attitudes or intentions.

Hybels and Weaver II(2001:72-74) summarized the listening processes as predicting, receiving message, attending, assigning meaning, remembering and assessing (see Figure $1)$. 


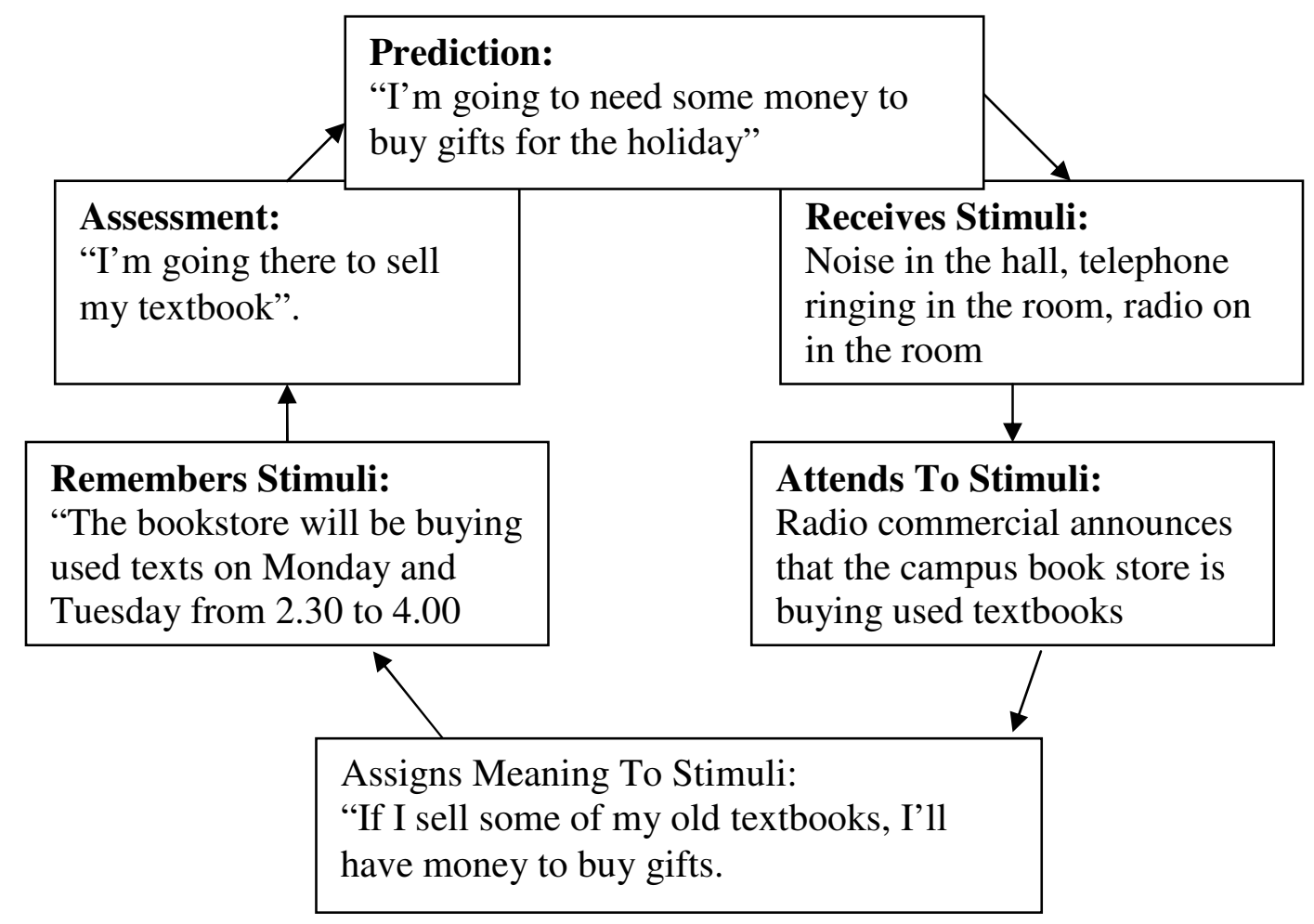

Figure 1 Listening Process: Adapted from Hybels and Weaver II, 2001.

\section{Predicting}

On the basis of your past experiences with someone, you can predict what to listen to. For one who always complains, you embrace yourself to listen to his complaints again. If you go to your lecturer with a late paper, you expect scolding so you prepare yourself to listen- not to argue or give excuses.

\section{Receiving Messages}

Listening, as said before is not hearing. We hear a lot of things (messages) like noise in the hallway, people arguing, a lecture going on, etc. but we do not listen to them. To receive a message, we must listen to filter out the irrelevant message.

\section{Attending}

Having listened, you attend to only the relevant and interesting messages. This is referred to as "selective attention". This is why a person in the midst of noise, music, television broadcast still listens to the one he prefers. 


\section{Assigning Meaning}

One assigns meaning to the message he decides to attend to. To assign meaning, you consider everything about the message- what was said, how it was said, consider the speaker's tone of voice, his facial expression and gestures. What are they telling? What is relevant in the message you are attending to. You can even ask Questions as regards the speaker's motives and know where it contrasts with your own belief.

\section{Remembering}

The next step in the listening process is remembering. What do you remember? A student should remember only the important points. As you listen to lectures, take note of the key points. If you take too many notes, it may interfere with your listening. Do not write down what you do not understand because you are not going to understand it when you look at it later. Rather stop and ask questions and clarifications.

\section{Assessing}

Assessment is an evaluation of what has happened. When you had predicted what will happen and it happened that way, you have learnt from experience. You can never submit papers late to your lecturer again as you have assessed the instructor's reaction. In an ideal listening situation, all these processes must be completed. Ineffective listening will bring about a breakdown in these processes.

\section{Ideal kinds of Listening}

Listening is a skill and like any other skill it must be learned and practiced. The basic reason why students/people spend their time listening is to gather information. It could be an empathic listening, listening for enjoyment, or precision listening. These could be achieved through active listening and critical listening.

\section{Active Listening}

To get the best of what is being said, one should be an active listener not a passive one. An active listener makes a mental outline of important points, thinks out questions or challenges to the point that has been made. Active listeners do better in schools than passive listeners who records but do not evaluate what he hears. An active also takes note but he evaluates, tie concepts together and distinguishes between the main idea and supporting ideas before writing them down. Active listening goes beyond the classroom. It is evident in interpersonal communication and involves looking at both literal and emotional meanings in what someone is saying. The listener makes use of both verbal and non-verbal cues to show the speaker that he is interested in what he is saying such as "is that so", "uh-uh", "Mmm", "I see", plus nonverbal cues such as nodding, smiling, frowning or clapping as the case may be. The active listener in interpersonal communication can also give feedback by asking questions or giving comments. He is involved; he is interested and can never be bored because he is a participant rather than an observer.

According to Hybels and Weaver II, an active listening student should be able to:

- Identify the central/main ideas in lectures

- Identify supporting materials which includes illustrations and examples.

- Form a mental outline of the central ideas and the supporting information and try to remember them. 
- Predict what will come next.

- Relate points to experience.

- Look for similarities and differences in relation to what you already know.

- Take notes and ask friendly questions to the speaker and seek clarification in things not understood.

A good student is an active listener who maximizes what he hears in listening situations by making efforts to arrive early and sits in front, and by fighting distractions as best as he can.

\section{Critical Listening}

When listens critically, he indulges in all the ingredients of active listening, but in addition evaluates and challenges what has been heard. This does not entail being rude as the challenge can be in the mind of the listener or direct but polite challenge of the speaker. There is a call for critical listening when you are been persuaded to do something or to take one product as against another you might have preferred, or cast a vote for someone or even make a choice of course after your career week in school.

A critical listener will first determine the speaker's motive, challenge and question ideas being presented by the speaker. Are they true? Where did he get his information from? He tries to distinguish facts from opinion. Finally, a critical listener assesses the message before taking decisions or positions based on the evidences and facts provided by the speaker.

\section{Conclusion}

To communicate effectively, one must first learn how to listen effectively. Students who have not listened attentively end up failing their exams. Active and critical listening skills must be encouraged in the classroom. All obstackles to effective listening should be minimized. The teacher in dealing with students should give a listening ear that is suitable to the situation, thereby winning their confidence. Mastery of the listening skills is an important step towards the mastery of other language skills which all together will lead to effective communication in an ESL/EFL classroom.

\section{References}

Campbell, Rex R. (1997) Attributes of Good Listening, Leadership: Getting It Done.

University of Missouri, www.ssu.missour.edu/faculty/RCampbell/leadership/chapter6.htm

Fruehling, Rosemary T. and Joan M. Lacombe. (2006) Communicating For Results. India, A. I. T. B. S. Publishers.

Hybels, Saundra and Richard L. Weaver II. (2001) Communicating Effectively New York: McGraw-Hill Higher Education.

Pandey, S. K. (2005)Teaching Communication. New Delhi: Commonwealth Publishers. Willis, J. (1981) Teaching English through English. London: Longman.

Wolvin, Andrew D. (1995) On Competent Listening, Listening Post, No.54, July, 1995.

Yagang, Fan (1996) Listening: Problems and Solution in Kral, Thomas (Ed.) Teacher Development: Making the Right Moves. U.S. Information Agency: English Language Programs Division,

Youaver, James B. III and Michelle D. Kirtley. (1995) Listening Styles and Empathy, Southern Communication Journal 60 (2) 